\title{
BENEFÍCIOS DA MELATONINA NA ENXAQUECA
}

Benefits of melatonin in migraines

Diana Bittencourt Bento,

Flávia Rigo.

Endereço para correspondência:

Diana Bittencourt Bento - Rodovia SC 438, n. 438, Bairro Cond'eu, Orleans, Santa Catarina. CEP: 88.870-000.

Email: dianabbento@hotmail.com

\section{RESUMO}

A enxaqueca (migrânea) é uma doença neurológica crônica e incapacitante. Sua fisiopatologia é multifatorial, e as crises são deflagradas por fatores desencadeantes, que variam na sua intensidade e diversidade. Mecanismos como o genético, hormonal, ambiental e comportamental são destacados, sendo que as bases biológicas ocorrem através da intermediação de neurotransmissores. Atualmente, não existe tratamento padronizado para o completo alívio dos sintomas da enxaqueca, apenas terapia que promove uma melhora significativa na qualidade de vida dos pacientes. A melatonina, produzida a partir da glândula pineal é um hormônio que está envolvido no controle de ritmos circadianos e exerce uma série de efeitos farmacológicos. A melatonina medeia suas ações através dos receptores de melatonina MT1 / MT2. As síndromes de dor crônica são frequentemente associadas à desincronização de ritmos circadianos e biológicos, que também causam distúrbios no ciclo sono-vigília. Os efeitos analgésicos mediados pela melatonina parecem envolver $\beta$-endorfinas, receptores GABA, receptores opióides e a via óxido nítricoarginina. A eficácia da melatonina como agente analgésico e ansiolítico foi demonstrado em vários modelos animais de dor. Estudos clínicos também estão evidenciando o efeito analgésico da melatonina, em diferentes condições patológicas, 
o que o torna uma alternativa promissora para o tratamento de dores refratárias, como a enxaqueca.

Palavras chaves: enxaqueca; terapêutica; melatonina.

\section{ABSTRAT}

Migraine (migraine) is a chronic and disabling neurological disease. Its pathophysiology is multifactorial, and crises are triggered by triggering factors, which vary in their intensity and diversity. Mechanisms such as genetic, hormonal, environmental and behavioral, are highlighted, and the biological bases occur through the intermediary of neurotransmitters. Currently, there is no standardized treatment for the complete relief of migraine symptoms, only therapy that promotes a significant improvement in patients' quality of life. Melatonin, produced from the pineal gland is a hormone that is involved in controlling circadian rhythms and exerts a number of pharmacological effects. Melatonin mediates its actions through the melatonin MT1 / MT2 receptors. Chronic pain syndromes are often associated with the desynchronization of circadian and biological rhythms, which also cause disturbances in the sleep-wake cycle. The analgesic effects mediated by melatonin seem to involve $\beta$-endorphins, GABA receptors, opioid receptors and the nitric oxide-arginine pathway. The efficacy of melatonin as an analgesic and anxiolytic agent has been demonstrated in several animal models of pain. Clinical studies are also demonstrating the analgesic effect of melatonin in different pathological conditions, making it a promising alternative for the treatment of refractory pains, such as migraine.

Keywords: migraines; therapy; melatonin

\section{INTRODUÇÃO}

As cefaleias são um importante problema de saúde pública no Brasil e no mundo, tendo em vista o alto impacto individual e social que essa condição clínica acarreta, devido a sua alta incidência e elevado potencial de cronificação, além de 


\section{Original}

\section{Atenção à saúde}

custos econômicos e redução na qualidade de vida que afeta quem a sente ${ }^{1}$. As cefaleias mais frequentes na população são as cefaleias primárias, que são aquelas manifestações de dor de cabeça em que a própria dor é a doença. Sendo que as mais comuns são as cefaleias do tipo tensional e a enxaqueca, atualmente conhecida como migrânea².

Segundo a Organização Mundial da Saúde (OMS, 2006), a cefaleia apresenta-se como a segunda queixa mais comum de dor. Estima-se que mais da metade da população mundial apresente algum tipo de cefaleia em determinada fase da vida². Esta patologia apresenta-se como uma doença neurovascular caracterizada por crises repetidas de dor de cabeça que podem ocorrer com uma frequência bastante variável. Uma crise típica de enxaqueca é reconhecida pela dor que envolve parte da cabeça ou toda cabeça, muitas vezes de caráter latejante ou em peso, de início progressivo, se acentuando em severidade com o passar do tempo, piora com qualquer atividade física e está frequentemente associada a náuseas, vômitos e desconforto com a exposição à luz, fotofobia, e sons altos, fonofobia. Estes episódios podem durar algumas horas ou até 3 dias e podem se acentuar no caso de mulheres no período menstrual. Um conjunto de sintomas neurológicos, conhecido pelo nome de aura, costuma acompanhar o quadro de dor ${ }^{1}$.

A enxaqueca é considerada uma doença crônica e incapacitante. Sua fisiopatologia é multifatorial ${ }^{4}$, e as crises são deflagradas por fatores desencadeantes, que variam na sua intensidade e diversidade. Mecanismos como o genético, hormonal, ambiental e comportamental são destacados, sendo que as bases biológicas ocorrem através da intermediação de neurotransmissores. O primeiro a ser considerado foi a serotonina, mas outras aminas como a dopamina e a noradrenalina também são consideradas. Assim com o complexo cérvico-trigemino-vascular ${ }^{5}$. A depressão alastrante cortical que corresponde ao fenômeno clínico da aura da enxaqueca ${ }^{6}$ associada ao mecanismo de hiperexcitabilidade cortical, que explica a fotofobia, fonofobia, osmofobia presentes na enxaqueca ${ }^{7}$, nos ressalta a importância do córtex cerebral na fisiopatologia desta enfermidade. Se a enxaqueca tem como base um cérebro hiperexcitável, sítios de ação responsáveis pela modulação da membrana celular neuronal são candidatos a terapêutica nas cefaléias ${ }^{8}$. Além dos neurotransmissores clássicos, outras moléculas vêm sendo implicadas na 


\section{Original}

\section{Atenção à saúde}

fisiopatologia da enxaqueca, como a melatonina ${ }^{9,10}$ e o óxido nítrico ${ }^{11}$. O mecanismo de hiperexcitabilidade cortical sofre importante influência dos aminoácidos excitatórios e inibitórios. O maior neurotransmissor excitatório no cérebro é o glutamato e o de maior importância inibitória é o ácido gama-amino-butírico (GABA) ${ }^{4}$.

Atualmente, não existe tratamento padronizado para o completo alívio dos sintomas da enxaqueca, apenas terapia que promove uma melhora significativa na qualidade de vida dos pacientes. $\mathrm{O}$ tratamento se baseia em dois tipos: o tratamento das crises e o tratamento preventivo e profilático. Por ser uma doença crônica, os pacientes em sua grande maioria fazem uso excessivo de medicamentos. Estudos epidemiológicos sugerem que até $4 \%$ da população utiliza analgésico e outros medicamentos excessivamente para tratamento de distúrbio da dor como a enxaqueca ${ }^{2}$. O uso excessivo de medicamentos ocorre em cerca de $1 \%$ da população adulta $^{12,13}$ e em $5 \%$ dos adolescentes da Europa, América do Norte e Ásia².

A melatonina ( $\mathrm{N}$-acetil-5-metoxitriptamina) é um hormônio produzido pela glândula pineal, está envolvido no controle dos ritmos circadianos e biológicos e respostas fisiológicas associadas, como sono, ansiedade e dor, exerce uma série de efeitos farmacológicos, e vem sendo evidenciados o seu efeito analgésico sobre a enxaqueca ${ }^{12}$. A melatonina parece mediar suas ações principalmente através de dois receptores de membrana, o MT1/MT2 pertencentes à família dos receptores da proteína $\mathrm{G}$ e um terceiro receptor MT3, que é uma quinina redutase ${ }^{15}$. A melatonina também ativa receptores nucleares de melatonina pertencente ao tipo de receptores órfãos RZR / ROR que inclui três subtipos $(\alpha, \beta, \gamma)^{16}$. Efeitos analgésicos mediados pela melatonina não tem seu mecanismo de ação bem conhecidos, embora parecem envolver as B-endorfinas, receptor GABA, receptores opióides e a via óxido nítricoarginina ${ }^{14}$. Os efeitos de potencialização do GABA, inibição do glutamato, modulação da ação da serotonina e a atuação como um anti-inflamatório podem ser úteis no tratamento da referida doença. A eficácia da melatonina como agente analgésico tem sido demonstrado em vários modelos animais de dor e isto levou ao uso de melatonina clinicamente em diferentes condições patológicas. A melatonina se mostrou eficaz na enxaqueca, fibromialgia, síndrome do intestino irritável, como analgésico indicando sua aplicação clínica ${ }^{14}$. 
Considerando que há forte relação entre sono e dor de cabeça, estando as síndromes de dor crônica frequentemente associadas à desincronização de ritmos circadianos e biológicos, que também causam distúrbios no ciclo sono-vigília, dessa forma, a capacidade de melatonina de regular os transtornos do sono, ou seja o ritmo circadiano, pode também pode ser útil para melhorar a fisiopatologia da dor de cabeça ${ }^{17}$. Diante disso, e considerando que a melatonina vem sendo reportada em vários estudos devido a seus vários efeitos biológicos, assim como o seu uso na prevenção e tratamento de enxaqueca ${ }^{18,19,20,21}$, percebe-se que este hormônio pode se tornar um aliado no tratamento e uma alternativa àqueles pacientes que não respondem à outros tratamentos convencionais. Devido a isso, este trabalho tem como finalidade uma revisão da literatura a fim de verificar o efeito analgésico da melatonina sobre a enxaqueca, assim como observar os mecanismos propostos.

\section{MÉTODOS}

Este artigo trata-se de uma revisão integrativa da literatura abordando o uso de melatonina na enxaqueca a fim de se obter uma ampla compreensão do fenômeno em estudo.

Foi utilizado como instrumento um levantamento de estudos científicos nacionais e internacionais sobre o tema proposto, a amostra foi escolhida por conveniência sendo incluídos artigos publicados entre 1994 e 2017 produzidos preferencialmente nos últimos sete anos, disponíveis em bases de dados tais como Medline, LILACS, PubMed e SciElo, usando como descritor as palavras chave: enxaqueca, tratamento da enxaqueca, melatonina, glândula pineal. A busca bibliográfica foi realizada entre o mês de maio e setembro de 2017.

\section{DESENVOLVIMENTO / RESULTADOS E DISCUSSÃO}

Vários estudos recentes sugerem que as alterações do ritmo circadiano desempenham um papel importante na patogênese das dores de cabeça. Nessa situação, a melatonina pode diminuir a frequência e intensidade das síndromes de dor através de mecanismos analgésicos inerentes e a normalização do ritmo circadiano. 


\section{Original}

\section{Atenção à saúde}

Os receptores de melatonina foram encontrados nos gânglios e núcleos do nervo do trigêmeo, sugerindo que a melatonina diminui a nocicepção vascular trigeminal ${ }^{10,32}$. A melatonina demonstrou efeito analgésico em vários estudos experimentais e ensaios clínicos. Os estudos sugerem que a normalização dos ritmos circadianos, que são conhecidamente desordenados nas síndromes de dor crônica, leva à melhora do sono e à ativação das capacidades adaptativas inerentes à melatonina. Por outro lado, há evidências de efeito analgésico inerente à melatonina realizado através de receptores e vários sistemas de neurotransmissores ${ }^{10}$.

A melatonina tem sido usada para tratar uma série de distúrbios primários de dor de cabeça, como enxaqueca, dor de cabeça tensional, dor de cabeça aguda, cefaleia primária. O nível de evidência que relatam a eficácia da melatonina no tratamento desses distúrbios variam ${ }^{9,22}$. Estudos observacionais reportam o papel da melatonina no tratamento da enxaqueca. Adultos com enxaqueca tem níveis baixos de melatonina comparados aos dias sem dor, e também àqueles com enxaqueca crônica apresentam níveis mais baixos de melatonina comparados aos que tem enxaqueca episódica23,24.

Vários estudos analisaram a associação entre secreção noturna de melatonina e enxaqueca. Um estudo envolvendo 146 pacientes com enxaqueca revelaram um nível urinário substancialmente inferior de 6-sulfatooxymelatonina (metabolito de melatonina) em pacientes com enxaqueca em comparação com um grupo de voluntários saudáveis ${ }^{23}$. A melatonina é considerada hormônio da escuridão, pois sua secreção pela glândula pineal é mais alta durante períodos da noite ${ }^{14}$. A melatonina foi sugerida para ter um papel importante na regulação da dor em condições fisiológicas normais, uma vez que tanto a percepção da dor como a secreção de melatonina são de natureza circadiana ${ }^{14}$. Além disso, a melatonina mostrou influenciar a percepção da dor ${ }^{15}$. Sugerindo uma forte ligação entre os níveis de melatonina noturno e a enxaqueca. Foi relatado, que o tratamento com melatonina devidamente controlado com doses apropriadas, levou a uma diminuição das dores de cabeça em $78,6 \%$ dos 328 pacientes que sofriam com distúrbios do sono e dor de cabeça, enquanto que os efeitos adversos (leve dor de cabeça) foram observados em 13,8\% dos 676 pacientes com apenas distúrbios do sono sem dor de cabeça ${ }^{25}$. 
Em relação a posologia alguns estudos já evidenciaram o uso de $3 \mathrm{mg}$ de melatonina duas vezes ao dia, administradas em crianças com cefaleia primária, conseguiu reduzir o número, a intensidade e a duração das crises de dor de cabeça. Foi sugerido que a melatonina possa ser considerada uma medicação profilática efetiva para uso em crianças com enxaqueca ${ }^{26}$. Além disso, em um ensaio clínico aberto, envolvendo 34 pacientes que sofriam de enxaqueca, foi avaliado a eficácia da melatonina na prevenção da enxaqueca. $\mathrm{O}$ uso profilático de $3 \mathrm{mg}$ de melatonina, administrado 30 minutos antes da hora de dormir, reduziu a intensidade da dor de cabeça, bem como a frequência e duração, com melhora clínica significativa em um mês ${ }^{19}$. Outro estudo, utilizou com sucesso a agomelatina, um agonista de melatonina, $25 \mathrm{mg} / \mathrm{dia}$ por 3 meses, que mostrou-se eficaz no tratamento de pacientes com enxaqueca na diminuição da frequência e duração das crises de enxaqueca ${ }^{27}$. Além disso, um estudo em modelo animal mostrou que a melatonina aumenta a liberação de $\beta$-endorfina pela glândula pituitária e foi observado que a naloxona, (antagonista opioide) impede a analgesia da melatonina ${ }^{28,29}$, demonstrando sugerindo que provavelmente os receptores opioides estão envolvidos na analgesia induzida pela melatonina.

Há evidencias, de que os efeitos centrais da melatonina envolvam a facilitação da transmissão GABAérgica pela modulação do receptor GABA. Os experimentos revelaram que a melatonina aumenta a afinidade de GABA nos receptores no cérebro de ratos ${ }^{30}$. A melatonina e seus análogos podem ativar receptores GABAérgicos e aumentar a concentração de GABA em $50 \%{ }^{31}$. Assim, os dados mostram uma interconexão significativa entre a melatonina e sistemas GABAérgicos, e alguns dos efeitos neurofarmacológicos da melatonina são, evidentemente, mediados por receptores de GABA e podem ser bloqueados pelos antagonistas do mesmo ${ }^{10}$. Sendo o GABA o principal neurotransmissor inibitório do SNC e estudos mostram que ele está aumentado em pacientes com enxaqueca crônica em relação ao controle, fortalecendo assim a hipótese de que ocorra uma provável resposta compensatória do sistema gabaérgico para equilíbrio da hiperexcitabilidade cortical ${ }^{4}$, indicando desse forma um possível mecanismo de ação da melatonina no tratamento da enxaqueca crônica e sendo essa via a possível explicação do mecanismo de ação da melatonina na enxaqueca. 


\section{CONCLUSÃO}

Entre a ampla gama de efeitos atribuídos à melatonina, seu papel na analgesia surge como importante devido às suas implicações clínicas. A melatonina e seus análogos tem se mostrados eficazes no tratamento de diversas tipos de dor, bem como a enxaqueca. Seja pelo reestabelecimento do ritmo circadiano, ou pela modulação dos receptores GABA entre outros mecanismos não tão bem elucidados. No entanto, estudos ainda mostram resultados insuficientes com relação a dose de melatonina capaz de prevenir ou tratar a enxaqueca. São necessários estudos contínuos e aprofundados acerca da aplicação da melatonina na enxaqueca afim de descobrir os reais mecanismos envolvidos e dessa forma poder contar com a melatonina na terapêutica e prevenção da enxaqueca.

\section{REFERÊNCIAS}

1. Stefane T, Alves NA, Emm FSFA, Hortense P. Influência de tratamentos para enxaqueca na qualidade de vida: revisão integrativa de literatura. Rev. Brasileira de Enfermagem. 2012:65(2).

2. Dyb G, Holmen TL, Zwart JA. Analgesic overuse among adolescents with headache: the Head-HUNT-Youth Study. Neurology. 2006;66(2):198-201.

3. Organização Mundial da Saúde. Benefits of physical activity. Geneva: WHO, 2006.

4. Peres MFPP, de Souza DSV, Rodrigues MM, Gonçalves AL, Castro Neto EF, Zukerman E, Naffah-Mazzacoratti MG. O papel do GABA na fisiopatologia da enxaqueca crônica. Migrâneas cefaléias. 2008;11(3):197-200.

5. Bartsch T, Goadsby PJ. The trigeminocervical complex and migraine: current concepts and synthesis. Curr Pain Headache Rep. 2003;7(5):371-6.

6. Sánchez del Rio M, Alvarez Linera J. Functional neuroimaging of headaches. Lancet Neurol. 2004;3(11):645-51.

7. Ambrosini A, de Noordhout AM, Sándor PS, Schoenen J. Electrophysiological studies in migraine: a comprehensive review of their interest and limitations. Cephalalgia. 2003;23 Suppl 1:13-31. 


\section{Original}

\section{Atenção à saúde}

8. Mercante JPP, Peres MFP, Guendler VZ, Corchs F, Bernik MA, Zukerman E. Impact of psychiatric comorbidity in the quality of life of chronic migraine patients. Migrâneas cefaléias 2005, 8(3):76.

9. Gelfand AA, Goadsby PJ. The role of melatonin in the treatment of primary headache disorders. Headache: The Journal of Head and Face Pain. 2016; 56.8: 1257-1266.

10. Danilov A, Kurganova J. Melatonin in chronic pain syndromes. Pain and therapy. 2016;5.1:1-17.

11. Olesen $\mathrm{J}$. The role of nitric oxide (NO) in migraine, tension-type headache and cluster headache. Pharmacol Ther. 2008;120 (2):157-71.

12. Diener HC, Limmroth V. Medication-overuse headache: a worldwide problem.Lancet Neurol. 2004;3(8):475-83.

13. Zwart JA, Dyb G, Hagen K, Svebak S, Holmen J. Analgesic use: a predictor of chronic pain and medication overuse headache: the Head-HUNT Study. Neurology. 2003;61(2):160-4.

14. Chen WW, Zhang X, Huang WJ. Pain Control by Melatonin: Physiological and Pharmacological Effects. Experimental and Therapeutic Medicine. 2016;12.4:19631968.

15. Srinivasan V, Pandi-Perumal SR, Spence DW, Moscovitch A, Trakht I, Brown GM, Cardinali DP. Potential use of melatonergic drugs in analgesia: Mechanisms of action. Brain Res Bull. 2010;81: 362-371.

16. Junker U, Wirz S. Review article: Chronobiology: Influence of circadian rhythms on the therapy of severe pain. J Oncol Pharm Pract. 2010;16: 81-87.

17. Reiter RJ, Tan DX, Galano A. Melatonin: Exceeding expectations. Physiology (Bethesda). 2014;29: 325-333.

18. Gonçalves AL, Ferreira AM, Ribeiro RT, Zukerman E, Cipolla-Neto J, Peres MFP. Randomised clinical trial comparing melatonin $3 \mathrm{mg}$, amitriptyline $25 \mathrm{mg}$ and placebo for migraine prevention. J Neurol Neurosurg Psychiatry. 2106; 87.10: 1127-1132.

19. Peres MF, Zukerman E, da Cunha TF, Moreira FR, Cipolla-Neto J. Melatonin, 3 $\mathrm{mg}$, is effective for migraine prevention. Neurology. 2004;63:757.

20. Alstadhaug KB, Odeh F, Salvesen R, et al. Prophylaxis of migraine with melatonin: a randomized controlled trial. Neurology. 2010;75:1527-32. 


\section{Original}

\section{Atenção à saúde}

21. Peres MF. Melatonin for migraine prevention. Curr Pain Headache Rep. $2011 ; 15: 334-5$.

22. The international classification of headache disorders, 3rd edition (beta version). Cephalalgia. 2013;33:629-808.

23. Masruha MR, Vieira DS, Minett TS, Cipolla-Neto J, Zukerman E, Vilanova LCP, Peres MFP. Low urinary 6-sulphatoxymelatonin concentrations in acute migraine. J Headache Pain. 2008;9(4):221-4.

24. Masruha MR, Lin J, de Souza Vieira DS, Minett TSC, Cipolla-Neto J, Zukerman E, Vilanova LCP, Peres MFP. Urinary 6-sulphatoxymelatonin levels are depressed in chronic migraine and several comorbidities. Headache. 2010;50:413-419.

25. Rovers J, Smits M, Duffy JF. Headache and sleep: Also assess circadian rhythm sleep disorders. Headache. 2014;54: 175-177.

26. Miano S, Parisi P, Pelliccia A, Luchetti A, Paolino MC, Villa MP. Melatonin to prevent migraine or tension-type headache in children. Neurol Sci. 2008;29: 285-287. 27. Tabeeva GR, Sergeev AV, Gromova SA. Possibilities of preventive treatment of migraine with MT1 and MT2 agonist and 5-HT2c receptor antagonista agomelatine (Valdoxan). Zh Nevrol Psikhiatr Im S S Korsakova. 2011;111(9):32-6.

28. Yu CX, Zhu B, Xu SF, Cao XD, Wu GC The analgesic effects of peripheral and central administration of melatonin in rats. Eur J Pharmacol. 2000;403:49-53.

29. Shavali S, Ho B, Govitrapong P, Sawlom S, Ajjimaporn A, Klongpanichapak S, Ebadi M. Melatonin exerts its analgesic actions not by binding to opioid receptor subtypes but by increasing the release of beta-endorphin an endogenous opioid. Brain Res Bull. 2005;64:471-479.

30. Wilhelmsen M, Amirian I, Reiter RJ, Rosenberg J, Go"genur I. Analgesic effects of melatonin: a review of current evidence from experimental and clinical studies. J Pineal Res. 2011;51(3):270-7.

31. Xu F, Li JC, Ma KC, Wang M. Effects of melatonin on hypothalamic gammaaminobutyric acid, aspartic acid, glutamic acid, beta-endorphin and serotonina levels in male mice. Biol Signals. 1995;4:225-31.

32. Srinivasan V, Lauterbach EC, Ho KY, Acuña DC, Zakaria R, Brzezinski A. Melatonin in antinociception: Its therapeutic applications. Curr Neuropharmacol. 2012;10: 167-178. 